\title{
Beneficiation of Beni-Khaled Limestone Ore for Beneficial Industrial Uses
}

\author{
Mohamed Abuel Kasem Mohamed ${ }^{1}$, Galal Abd El Azim Ibrahim ${ }^{1}$, \\ Ahmed Mohamed Ebrahim Rizk ${ }^{1}$, Mahmoud Mohamed Ahmed ${ }^{1}$, Ahmed Mohamed El Nozahi², \\ Nagui Aly Abdel-khalek ${ }^{3}$, Hasan Bakheat ${ }^{4}$ \\ ${ }^{1}$ Center of Evaluation and Upgrading Ore Quality in South Valley, Department of Mining and Metallurgical Engineering, Faculty of \\ Engineering, Assiut University, Assiut, Egypt \\ ${ }^{2}$ Council of Research for Industrial Technologies in the Egyptian Academy of Scientific Research and Technology, Cairo, Egypt \\ ${ }^{3}$ Central Metallurgical Research and Development Institute (CMRDI), Cairo, Egypt \\ ${ }^{4}$ Exploration and Evaluation of Mineral Deposit, Egyptian Mineral Resources Authority, Cairo, Egypt
}

Email address:

mohamabu2001@gmail.com (M. A. K. Mohamed)

\section{To cite this article:}

Mohamed Abuel Kasem Mohamed, Galal Abd El Azim Ibrahim, Ahmed Mohamed Ebrahim Rizk, Mahmoud Mohamed Ahmed, Ahmed Mohamed El Nozahi, Nagui Aly Abdel-khalek, Hasan Bakheat. Beneficiation of Beni-Khaled Limestone Ore for Beneficial Industrial Uses. International Journal of Mineral Processing and Extractive Metallurgy. Vol. 3, No. 3, 2018, pp. 47-59. doi: 10.11648/j.ijmpem.20180303.11

Received: July 26, 2018; Accepted: August 16, 2018; Published: October 12, 2018

\begin{abstract}
Limestone ore can be considered as an important source for mineral wealth in Egypt. Using wisdom for extracting these ores supports the national income of Egypt, Where, more than fifty million tons are produced per year. Most of this amount consumes in cement production and iron and steel industry. Beni-khaled quarries El-Menya Governorate, follows the Egyptian Iron and Steel Company, have more than 8 million tons of $(-4+1)$ and $(-1+0.0) \mathrm{cm}$ accumulated in the site. Consequently, the main objective of this study is the beneficiation of this piled amount to maximize its beneficial industrial uses. Using crushing and grinding, dry magnetic separation, and calcination techniques produced an ore agrees with the needs of many industries, which increase the national income and solve the current environmental problems in this area.
\end{abstract}

Keywords: Limestone Industrial Uses, Cement Industry, Limestone Beneficiation

\section{Introduction}

Limestone is one of the important and common uses industrial ore. In addition to its well-known use in construction and building either as it is or as an aggregate for concrete mixtures and roads paving, it is the main component in the cement industry raw meal [1-8].

Still remain the most important industrial uses of limestone, as it is considered as a necessary material for more than hundred industry such as metallurgical industries, glass, food industries, chemical industries and as a filling material, in addition to its environmental purposes [9-11].

Egypt produces more than fifty million tons per year. Production of these ores by haphazard methods without any identification to their physical and mechanical properties deteriorates the pure types of this ore [4-6].
Beni-Khaled quarries, El-Menya Governorate follows the Egyptian Iron and Steel Company, produces $(-8+4) \mathrm{cm},(-$ $4+1) \mathrm{cm}$ and $(-1+0) \mathrm{cm}$ of limestone sizes. The largest size ($8+4) \mathrm{cm}$ charges to iron and steel company for melting the iron ores. The two other sizes $(-4+1) \mathrm{cm}$ and $(-1+0.0) \mathrm{cm}$ are stored in different places beside or near to the crushers. Nowadays, there are more than 8 million tons from the two other sizes accumulated in the site.

Some individual efforts are tired to use $(-4+1) \mathrm{cm}$ size in roads paving. The finest size $(-1+0.0) \mathrm{cm}$ is tried in cement brick and glass making industries by individual efforts of some contractors. Figure 1 shows the current flowsheet for preparation, crushing and size classification of Beni-Khaled Limestone ore. 


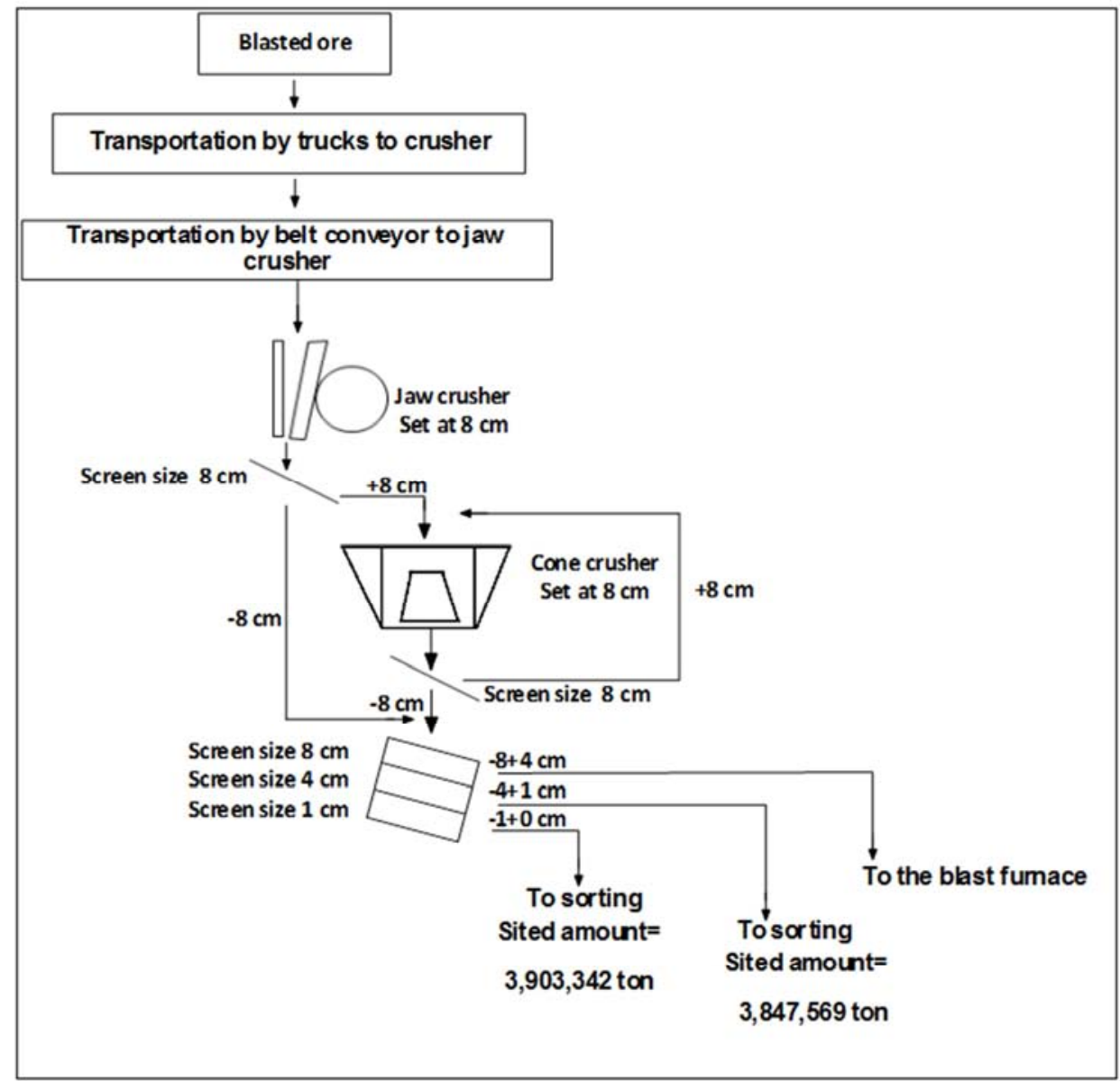

Figure 1. Current flowsheet for preparation of Beni-Khaled limestone ore.

Representative samples of these mentioned sizes are obtained from the quarries. Table 1 shows the size distribution of $(-4+1) \mathrm{cm}$ and $(-4+0.0) \mathrm{cm}$ sizes. Table 2 illustrates the mean chemical composition of the different elements for the three mentioned sizes.

Table 1. Particle size distribution of $(-4+1) \mathrm{cm}$ and $(-1+0.0) \mathrm{cm}$ sizes forBeni-Khaled Limestone ore.

\begin{tabular}{llll}
\hline Size $(-\mathbf{4}+\mathbf{1}) \mathbf{~ c m}$ & weight, $\%$ & Size (-1+0) cm & Size fraction, mm \\
\cline { 3 - 4 } Size fraction, $\mathbf{~ m m}$ & 02 & $(40+10)$ & 03 \\
\hline$(-80+40)$ & 52 & $(-10+5)$ & 13 \\
$(-40+30)$ & 39 & $(-5+3)$ & 46 \\
$(-30+20)$ & 07 & $(-3+0)$ & 38 \\
$(-20+10)$ & 100 & Sum & 100 \\
Sum & & & \\
\hline
\end{tabular}

Table 2. Mean chemical analysis for the different elements in the produced size fractions of Beni-Khaled Limestone ore.

\begin{tabular}{|c|c|c|c|c|c|c|c|c|c|}
\hline \multirow{2}{*}{ Sample } & \multirow{2}{*}{ Size fraction, $\mathrm{cm}$} & \multicolumn{8}{|c|}{ Chemical Composition } \\
\hline & & $\mathrm{SiO}_{2} \%$ & $\mathrm{CaO} \%$ & $\mathrm{MgO} \%$ & $\mathrm{R}_{2} \mathrm{O}_{3}\left(\mathrm{Fe}_{2} \mathrm{O}_{3}+\mathrm{Al}_{2} \mathrm{O}_{3}\right) \%$ & $\mathrm{Cl} \%$ & $\mathbf{S \%}$ & $\mathbf{P \%}$ & LOI\% \\
\hline 1 & $(-8+4)$ & 0.76 & 54.41 & 0.59 & 0.60 & 0.08 & 0.03 & 0.04 & 43.05 \\
\hline 3 & $(-1+0)$ & 0.47 & 52.68 & 0.78 & 2.17 & 0.12 & 0.03 & 0.03 & 40.56 \\
\hline
\end{tabular}

Consequently:

The main objective of this investigation is to study the possibility of using these piled amounts of limestone ore $(8$ million tons) of $(-4+1) \mathrm{cm}$ and $(-1+0.0) \mathrm{cm}$ sizes in suitable industrial uses. $(-8+4) \mathrm{cm}$ size is not full charges to the iron and steel company but it depends on the need of the company. Maximization of the benefit of the ore utilization is also intended. These purposes increase the national income and solve the environmental problem of this site.

\section{Experimental Work (Methodology)}

Samples of $(-8+4) \mathrm{cm},(-4+1) \mathrm{cm}$, and $(-1+0) \mathrm{cm}$ were obtained from the site. The following tests were applied on 
these specimens:

a. Petrographical Description.

b. Crushing operation tests using jaw and roll crushers.

c. Grinding using hammer and pebble mills.

d. Low intensity wet magnetic separation using Davis magnetic tube.

e. High intensity dry magnetic separation using Dry Belt Boxmag Separator.

f. Calcination processes.

\section{Results and Discussions}

\subsection{Petrographical Description of the Studied Samples}

This description has been done by the central laboratories of the Egyptian Geological Surveying authority as follows:

Rock name: Fossiliferous (formaniferal) limestone.

Rock type: Organic carbonate, sedimentary rock.

Texture: Huge amounts of microfossils of different sizes and shapes (mainly foramininfera) are cemented by very fine to fine-grained carbonates (calcite and dolomite).

\section{Mineral composition:}

The rock is composed of calcite and dolomite as the essential mineral constituents with rare amounts of quartz and traces of iron oxides.

Calcite and dolomite present the matrix of the rock. Quartz presents as very fine grained, anhedral crystals scattered in the carbonates matrix. Microfossils and shell fragments (mostly as foramininfera) are present in huge amount of different sizes and shapes and cemented with micritematrix and/or dolomite (in some parts). Few pores and fractures are observed in the sample. Carbonate minerals are slightly stained by traces of iron oxides in some parts.

Alteration: No significant alteration was observed.

Opaque minerals: Present in rare amount, as very fine grained aggregate and single subhedral crystals of goethite and hematite.

Goethite: Sometimes occurs as staining mineral over carbonate.

Sulphides: (most probably pyrite) present as very fine speaks or tiny spots in carbonate.

\subsection{Crushing and Grinding Results}

\subsubsection{Primary and Secondary Crushing Stages}

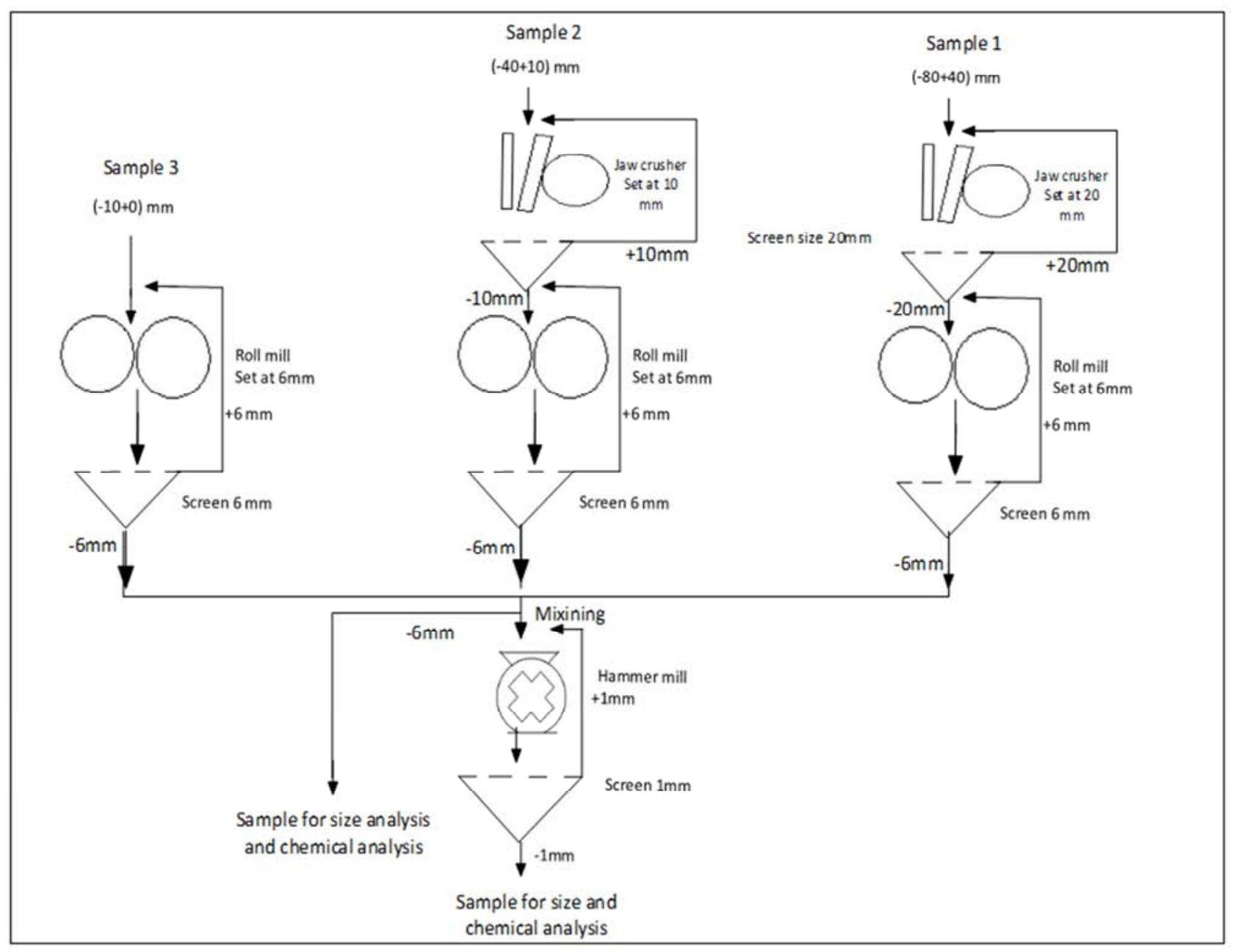

Figure 2. Crushing and grinding operations of Beni-Khaled Limestone ore. 
The first sample of size $(-8+4) \mathrm{cm}$ was crushed using a jaw crusher machine with a set adjusted at $20 \mathrm{~mm}$ in a closed circuit with a screen. The product $(-20+0) \mathrm{mm}$ was fed to a roll crusher of $6 \mathrm{~mm}$ opening in a closed circuit with a screen. The second sample of $(-4+1) \mathrm{cm}$ size was crushed using a jaw crusher with a set adjusted at $10 \mathrm{~mm}$ in a closed circuit. The product $(-10+0) \mathrm{mm}$ was secondary crushed using a roll mill with a set adjusted at $6 \mathrm{~mm}$ in a closed circuit. The third sample of $(-10+0.0) \mathrm{cm}$ was crushed using the roll mill machine to $-6 \mathrm{~mm}$ product in a closed circuit system.
The same size $(-6+0.0) \mathrm{mm}$ were mixed thoroughly. Representative samples of $(-6+0.0) \mathrm{mm}$ were fed to a closed circuit hammer mill to obtain $(-1+0) \mathrm{mm}$ size as shown in Figure 2.

A representative sample from the product of crushing which has $(-6+0.0) \mathrm{mm}$ size was size analyzed using a nest of screens of 4,2 and $1 \mathrm{~mm}$, then a representative sample of each size was chemically analyzed using XRF. Table 3 illustrate the results of size and chemical analyses of the mentioned sizes.

Table 3. Particle size analysis and mean chemical analysis for crushed (-6+0) $\mathrm{mm}$.

\begin{tabular}{|c|c|c|c|c|c|c|c|c|}
\hline \multirow{2}{*}{ Size fraction, $\mathbf{m m}$} & \multirow{2}{*}{ wt., \% } & \multicolumn{7}{|c|}{ Grade, \% } \\
\hline & & $\mathrm{CaO} \%$ & $\mathrm{SiO}_{2} \%$ & MgO\% & $\mathrm{Fe}_{2} \mathrm{O}_{3}, \%$ & $\mathrm{Al}_{2} \mathrm{O}_{3}, \%$ & $\mathrm{CaCO}_{3}, \%$ & Purity degree \\
\hline$(-6+4)$ & 10.94 & 55.51 & 0.33 & 0.16 & 0.08 & 0.18 & 99.13 & High purity \\
\hline$(-4+2)$ & 27.13 & 55.64 & 0.32 & 0.13 & 0.08 & 0.16 & 99.36 & High purity \\
\hline$(-2+1)$ & 20.17 & 54.62 & 0.75 & 0.19 & 0.14 & 0.2 & 97.54 & Medium purity \\
\hline$(-1+0)$ & 41.76 & 54.84 & 0.77 & 0.22 & 0.21 & 0.33 & 97.93 & Medium purity \\
\hline Head sample & 100 & 55.16 & 0.55 & 0.19 & 0.11 & 0.22 & 98.50 & Medium purity \\
\hline
\end{tabular}

A representative sample of the hammer milled ore of $(-1+0) \mathrm{mm}$ size was analyzed on $0.5,0.2$ and $0.063 \mathrm{~mm}$ nest of screens, then a representative sample of each size was chemically analyzed with XRF. Table 4. clears the results of size and chemical analyses of these samples.

Table 4. Particle size analysis mean chemical analysis for each size of the ground $(-1+0.0)$ cm product.

\begin{tabular}{lllllllll}
\hline \multirow{2}{*}{ Size fraction, $\mathbf{m m}$} & \multirow{2}{*}{ wt., \% } & \multicolumn{2}{c}{$\mathbf{G r a d e}, \boldsymbol{\%}$} & & & & \\
\cline { 3 - 8 } & $\mathbf{C a O} \%$ & $\mathbf{S i O}_{\mathbf{2}} \%$ & $\mathbf{M g O} \%$ & $\mathbf{F e}_{\mathbf{2}} \mathbf{O}_{\mathbf{3}}, \boldsymbol{\%}$ & $\mathbf{A l}_{\mathbf{2}} \mathbf{O}_{\mathbf{3}}, \mathbf{\%}$ & $\mathbf{C a C O}_{\mathbf{3}}, \boldsymbol{\%}$ & Purity degree \\
\hline$(-1+0.5)$ & 23.98 & 55.28 & 0.40 & 0.17 & 0.09 & 0.16 & 98.71 & High purity \\
$(-0.5+0.2)$ & 30.41 & 55.04 & 0.53 & 0.17 & 0.13 & 0.19 & 98.29 & Medium purity \\
$(-0.2+0.063)$ & 28.04 & 55.17 & 0.59 & 0.18 & 0.11 & 0.23 & 98.52 & High purity \\
$(-0.063+0)$ & 17.57 & 55.01 & 0.55 & 0.18 & 0.11 & 0.22 & 98.23 & Medium purity \\
Head sample & 100 & 55.14 & 0.51 & 0.17 & 0.11 & 0.21 & 98.46 & Medium purity \\
\hline
\end{tabular}

Figures 3 and 4 illustrate the final results of the cumulative weight percent of the crushed and ground products respectively.

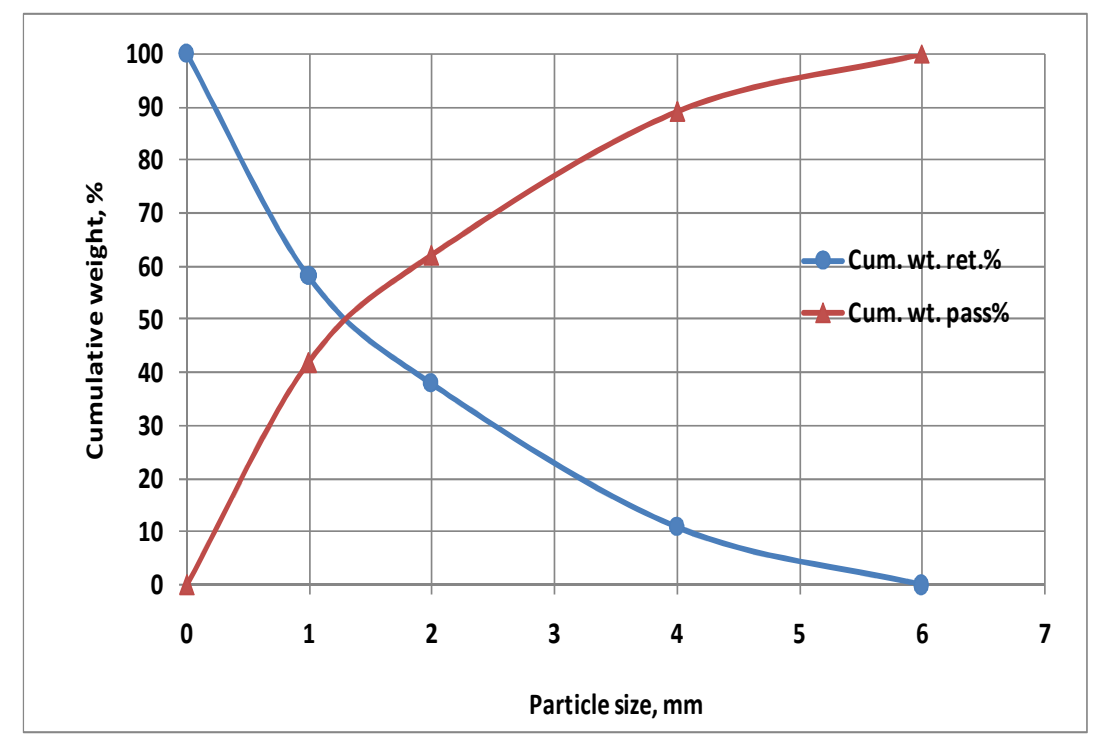

Figure 3. Final particle size distribution (Cum.wt. \% retained and passed) for crushed limestone. 


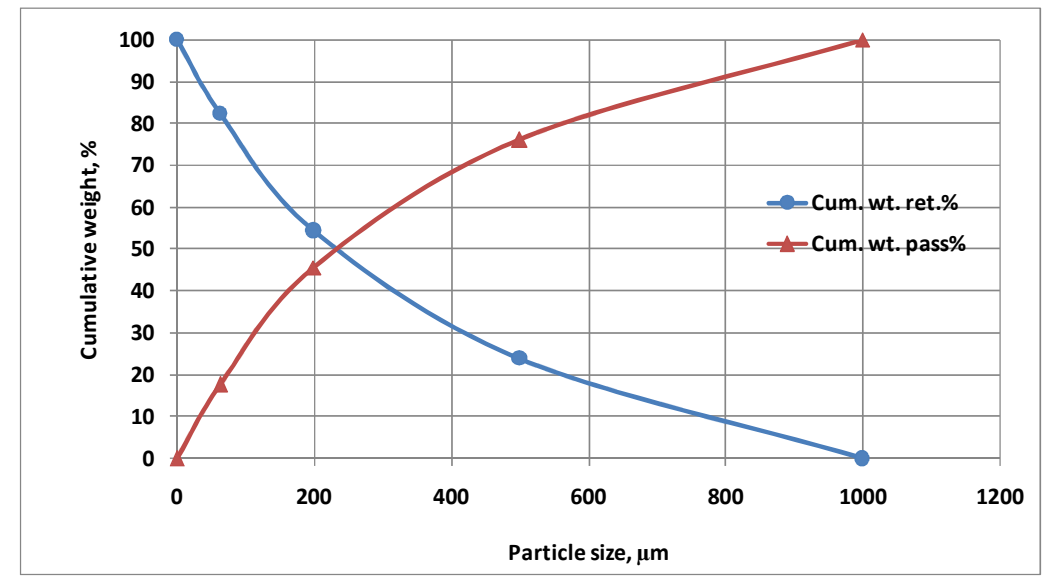

Figure 4. Final particle size distribution (Cum.wt. \% retained and passed) for ground limestone.

Table 3 and Figure 5 show the particle size and chemical analysis of each size of the crushed products.

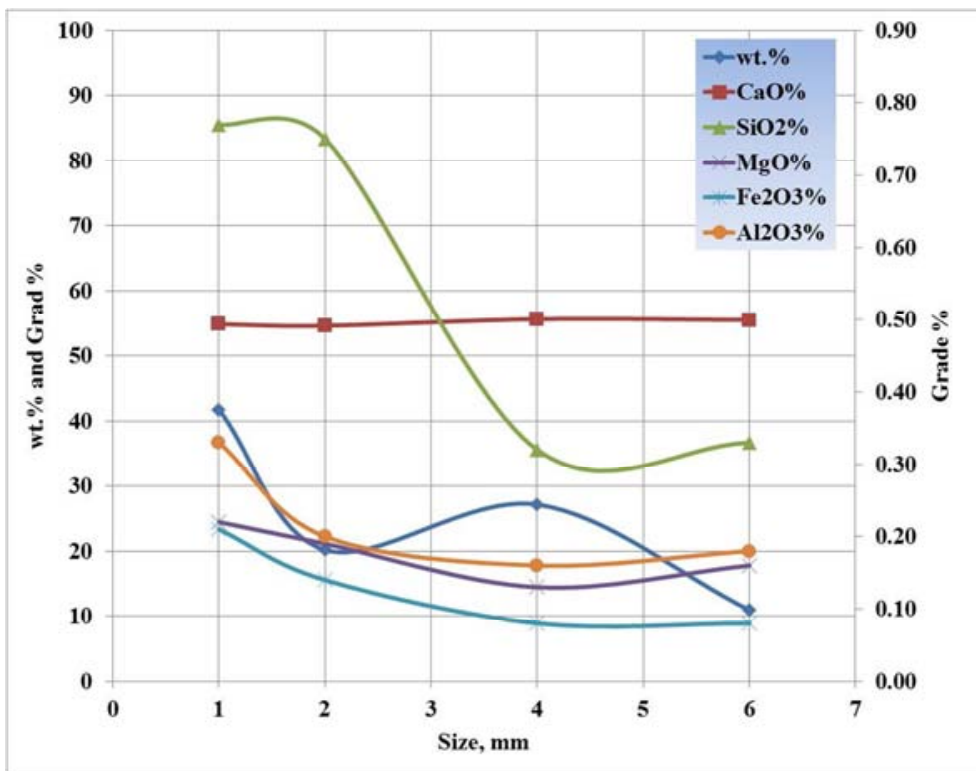

Figure 5. Particle size distribution and mean grade of each element for the crushed limestone size (-6+0) mm.

Table 4 and Figure 6 show the final results of the size and chemical analyses of the ground product.

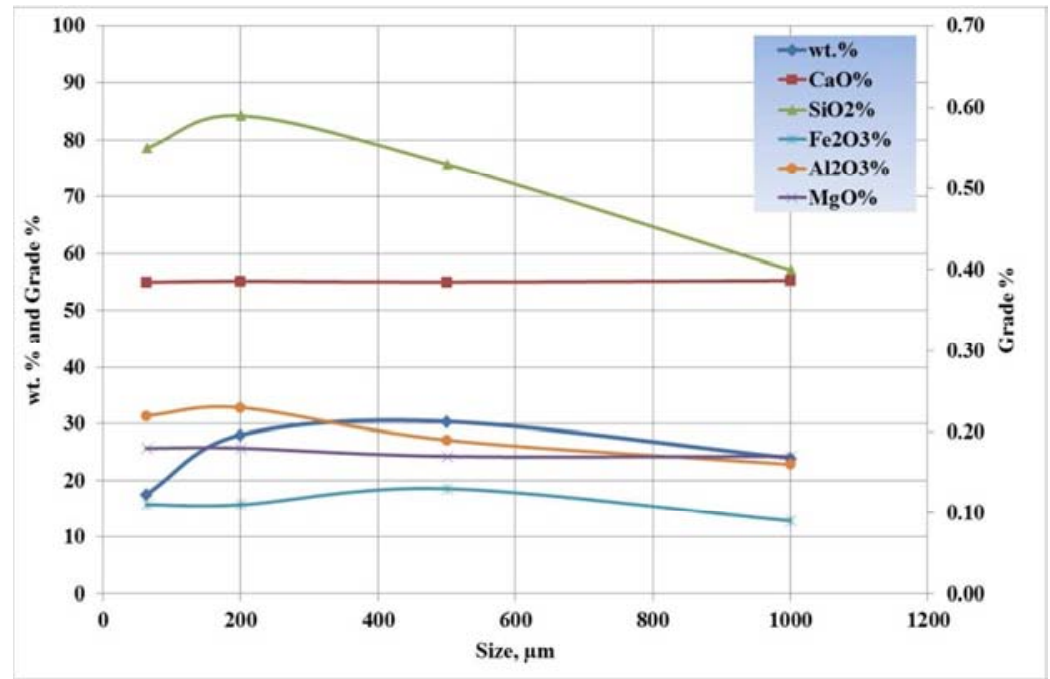

Figure 6. Particle size distribution and mean grade of each element for the ground limestone $(-1+0) \mathrm{mm}$. 
Table 5 and Figure 7 show the cumulative weight \% passed of particles and cum.\% of chemical analysis for each element in the crushed of $(-6+0) \mathrm{mm}$ product.

Table 5. Cum.wt. \% passed of particles and their chemical analysis for each element in the crushed limestone.

\begin{tabular}{|c|c|c|c|c|c|c|}
\hline \multirow{2}{*}{ Size fraction, mm } & \multirow{2}{*}{ c.w.p. $\%$} & \multicolumn{5}{|c|}{ Cumulative recovery, \% } \\
\hline & & $\mathrm{CaO} \%$ & $\mathrm{SiO}_{2} \%$ & $\mathrm{MgO} \%$ & $\mathrm{Fe}_{2} \mathrm{O}_{3}, \%$ & $\mathrm{Al}_{2} \mathrm{O}_{3}, \%$ \\
\hline$(-6)$ & 100 & 100 & 100 & 100 & 100 & 100 \\
\hline$(-4)$ & 89.06 & 88.98 & 93.94 & 90.44 & 94.02 & 91.84 \\
\hline$(-2)$ & 61.93 & 61.57 & 79.37 & 71.16 & 79.20 & 73.85 \\
\hline$(-1)$ & 41.76 & 41.57 & 53.98 & 50.21 & 59.91 & 57.12 \\
\hline
\end{tabular}

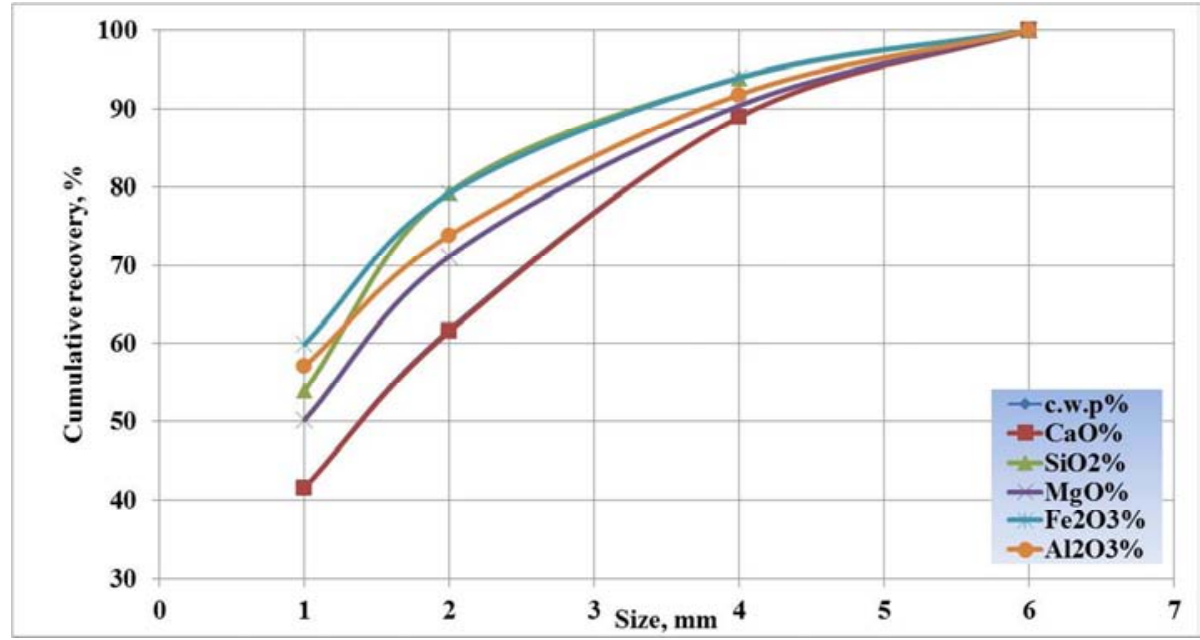

Figure 7. Cum.wt. \% passed of particles and their chemical analysis for each element in the crushed limestone.

Figure 8 and Table 6 show the cumulative weight \% passed of particles and Cum.wt.\% passed of each element in the ground limestone.

Table 6. Cum.wt. \% passed of particles and their chemical analysis for each element in the ground limestone.

\begin{tabular}{|c|c|c|c|c|c|c|}
\hline \multirow{2}{*}{ Size fraction, $\mu \mathrm{m}$} & \multirow{2}{*}{ c.w.p. $\%$} & \multicolumn{5}{|c|}{ Cumulative recovery, \% } \\
\hline & & $\mathrm{CaO} \%$ & $\mathrm{SiO}_{2} \%$ & $\mathrm{MgO} \%$ & $\mathrm{Fe}_{2} \mathrm{O}_{3}, \%$ & $\mathrm{Al}_{2} \mathrm{O}_{3}, \%$ \\
\hline$(-1000)$ & 100 & 100 & 100 & 100 & 100 & 100 \\
\hline$(-500)$ & 76.01 & 75.95 & 81.52 & 76.64 & 80.60 & 80.74 \\
\hline$(-200)$ & 45.61 & 45.59 & 50.48 & 47.03 & 45.08 & 51.75 \\
\hline$(-63)$ & 17.57 & 17.53 & 18.61 & 18.11 & 17.36 & 19.39 \\
\hline
\end{tabular}

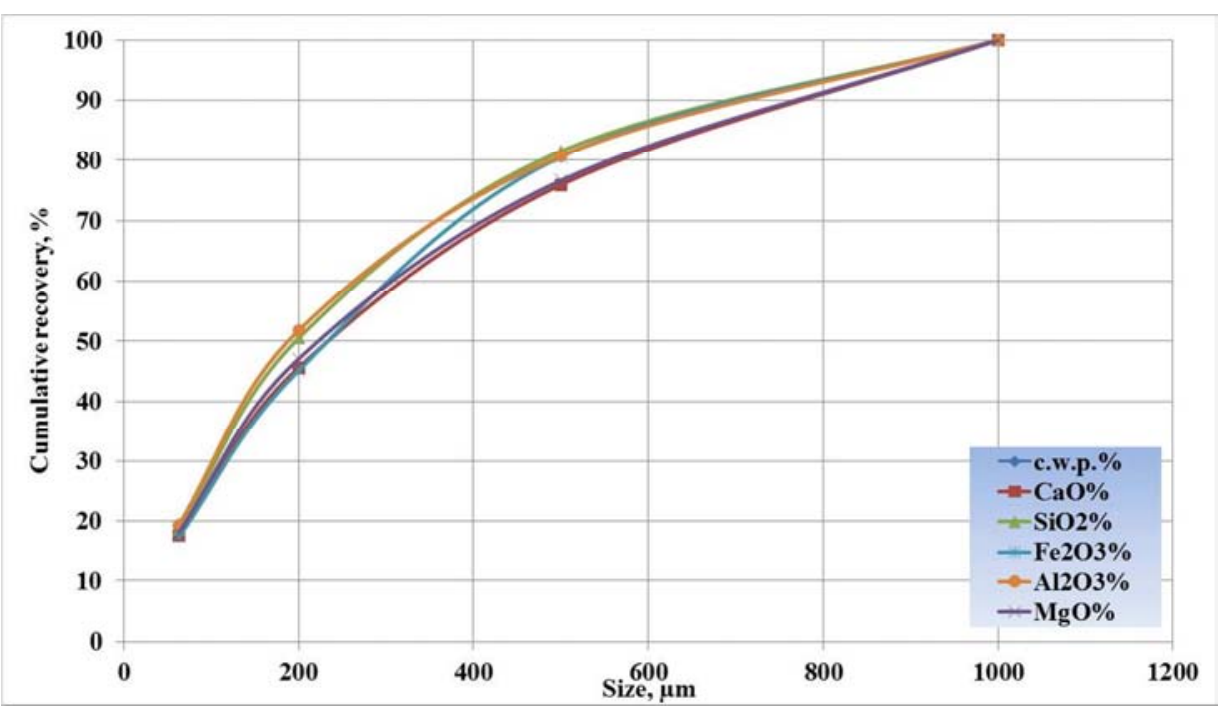

Figure 8. Cum.wt.\% passed of particles and their chemical analysis for each element in the ground limestone. 
From the results of Table 3 it is clear that, it is possible to add the high purity sizes $(-6+4) \mathrm{mm}$ and $(-4+2) \mathrm{mm}$ which represent $38.07 \%$ from the head sample to obtain a product suitable for some industrial beneficial uses. These results are shown in Table 7.

Table 7. Mean chemical composition for the most important elements that produced from adding (-6+4) $\mathrm{mm}$ and (-4+2) $\mathrm{mm}$ sizes.

\begin{tabular}{|c|c|c|c|c|c|c|c|c|}
\hline \multirow{2}{*}{ Size fraction, $\mathbf{m m}$} & \multirow{2}{*}{ wt., $\%$} & \multicolumn{7}{|c|}{ Grade, $\%$} \\
\hline & & $\mathrm{CaO} \%$ & $\mathrm{SiO}_{2} \%$ & MgO $\%$ & $\mathrm{Fe}_{2} \mathrm{O}_{3}, \%$ & $\mathrm{Al}_{2} \mathrm{O}_{3}, \%$ & $\mathrm{CaCO}_{3}, \%$ & Purity degree \\
\hline$(-6+4) \&(-4+2)$ & 38.07 & 55.60 & 0.32 & 0.14 & 0.08 & 0.17 & 99.29 & High purity \\
\hline
\end{tabular}

According to the Egyptian General Authority of Mineral Wealth classification [1]. the chemical composition from adding these two sizes Follows to super high purity $(98.85$ $\mathrm{CaCO}_{3}$ ), but according to the British Geological surveying Authority [13] it follows the high purity classification due to occurrence of little high contents of $\mathrm{Fe}_{2} \mathrm{O}_{3}$ and $\mathrm{Sio}_{2}$. Consequently, adding these two products makes the mixture suitable for paints, paper, plastic, rubber, Adhesives and sealants, and Agriculture and animal feed industries [12-13]. The same results of Table 7 clear that this product can not be used in food industry due to the high ratio of $\mathrm{Sio}_{2}$, where the permissible ratio ranges between 0.10 and $0.12 \%$. It can not be used also in ceramics industry due to the ratios of $\mathrm{Sio}_{2}$ and $\mathrm{Fe}_{2} \mathrm{O}_{3}$ are higher than the required ones.
From the results of Table 3 it is clear also that the two sizes of medium purity $(-2+1) \mathrm{mm}$ and $(-1+0) \mathrm{mm}$ shown in Table 8 , which represent $61.93 \%$ of the head sample produces a beneficial product. The Egyptian General Authority of Mineral Wealth classified this product in a purity degree $\left(\mathrm{CaCO}_{3}\right.$ 97-98.5\%), but the British Geological Surveying Authority classified this product as a medium purity due to the occurrence of little high ratios of $\mathrm{Sio}_{2}$ and $\mathrm{Fe}_{2} \mathrm{O}_{3}$. Chemical analysis of the final product clears that; it can be used in some industries after reducing the $\mathrm{Fe}_{2} \mathrm{O}_{3}$ from $0.19 \%$ to $0.10 \%$ by using high intensity magnetic separator such as paint, rubber, adhesives and sealants, and Agriculture and animal feed industries [12-15].

Table 8. Mean chemical composition for the most important elements in the mixture of (-6+4) mm and (-4+2) mm sizes.

\begin{tabular}{|c|c|c|c|c|c|c|c|c|}
\hline \multirow{2}{*}{ Size fraction, $\mathrm{mm}$} & \multirow{2}{*}{ wt., \% } & \multicolumn{7}{|c|}{ Grade, \% } \\
\hline & & $\mathrm{CaO} \%$ & $\mathrm{SiO}_{2} \%$ & $\mathrm{MgO} \%$ & $\mathrm{Fe}_{2} \mathrm{O}_{3}, \%$ & $\mathrm{Al}_{2} \mathrm{O}_{3}, \%$ & $\mathrm{CaCO}_{3}, \%$ & Purity degree \\
\hline$(-2+1) \&(-1+0)$ & 61.93 & 54.77 & 0.76 & 0.21 & 0.19 & 0.29 & 97.80 & Medium purity \\
\hline
\end{tabular}

But it can not be used in paper, plastic, and foods due to the higher value of $\mathrm{Sio}_{2}$ content. It can not be also used in ceramic industry due to the higher ratio of $\mathrm{Sio}_{2}$ and $\mathrm{Fe}_{2} \mathrm{O}_{3}$ and the lower ratio of $\mathrm{Cao}$ and $\mathrm{CaCO}_{3}$ content [13].

From the results in Table 4. it is clear that it is possible to add the two sizes of high purity $(-1+0.5) \mathrm{mm}$ and ($0.20+0.063) \mathrm{mm}$ which represent more than the half of the head sample $(52.03 \%)$ to obtain a product proper for some industries [13]. The final results are shown in Table 9.

Table 9. Mean chemical composition for the most important elements produced from adding the (-1+0.5) $\mathrm{mm}$ and (0.2+0.063) mm two sizes.

\begin{tabular}{|c|c|c|c|c|c|c|c|c|}
\hline \multirow{2}{*}{ Size fraction, $\mathbf{m m}$} & \multirow{2}{*}{ wt., \% } & \multicolumn{7}{|c|}{ Grade, \% } \\
\hline & & $\mathrm{CaO} \%$ & $\mathrm{SiO}_{2} \%$ & MgO $\%$ & $\mathrm{Fe}_{2} \mathrm{O}_{3}, \%$ & $\mathbf{A l}_{2} \mathrm{O}_{3}, \%$ & $\mathrm{CaCO}_{3}, \%$ & Purity degree \\
\hline$(-1+0.5) \&(-0.2+0.063)$ & 52.03 & 55.22 & 0.50 & 0.18 & 0.10 & 0.20 & 98.61 & High purity \\
\hline
\end{tabular}

According to the Egyptian General Authority of Mineral Wealth classification [1], the chemical composition of the mixture produced from blending these two sizes follows the super purity category $\left(98.5 \% \mathrm{CaCO}_{3}\right)$, But according to the British Geological Surveying Authority considered as a high purity category due to the little higher ratios of $\mathrm{Sio}_{2}$ and $\mathrm{Fe}_{2} \mathrm{O}_{3}$ contents.

The chemical composition of the mixture (Table 9) clears the possibility of its use in paints, plastic, rubber, adhesives and sealants, and agriculture and animal food industries [15-16].

This product can not be used in paper or food industries due to the high percentage of $\mathrm{Sio}_{2}(0.10-0.12 \%)$. It can not be also used in ceramics industry due to the higher ratio of $\mathrm{Sio}_{2}$ and the lower ratio of $\mathrm{Cao}$ and $\mathrm{CaCO}_{3}$ [16]. The results of Table 4. clears that, it is possible to add the two size ($0.5+0.2) \mathrm{mm}$ and $(-0.063+0) \mathrm{mm}$ which represent $47.97 \%$ of the head sample. Chemical analysis of this mixture is shown in Table 10

Table 10. Mean chemical composition for the most important elements produced from $(-0.5+0.2) \mathrm{mm}$ and $(-0.063+0) \mathrm{mm}$ two sizes

\begin{tabular}{|c|c|c|c|c|c|c|c|c|}
\hline \multirow{2}{*}{ Size fraction, mm } & \multirow{2}{*}{ wt., \% } & \multicolumn{7}{|c|}{ Grade, \% } \\
\hline & & $\mathrm{CaO} \%$ & $\mathrm{SiO}_{2} \%$ & $\mathrm{MgO} \%$ & $\mathrm{Fe}_{2} \mathrm{O}_{3}, \%$ & $\mathrm{Al}_{2} \mathrm{O}_{3}, \%$ & $\mathrm{CaCO}_{3}, \%$ & Purity degree \\
\hline$(-0.5+0.2) \&(-0.063+0)$ & 47.97 & 55.03 & 0.54 & 0.17 & 0.12 & 0.20 & 98.27 & Medium purity \\
\hline
\end{tabular}

According to the Egyptian General Authority of Mineral Wealth classification and from the chemical composition of adding these two sizes, it is clear that this mixture follows the high purity category ( $\mathrm{CaCO} 3$ ranges from $97 \%$ to $98.5 \%$ ), but according to the British classification it follows the medium purity due to the little high percentage of $\mathrm{Fe}_{2} \mathrm{O}_{3}$ $(0.12 \%)$ than the permissible $(0.10 \%)$.

From the chemical composition and after lowering the 
$\mathrm{Fe}_{2} \mathrm{O}_{3}$ to the acceptable limit by using the high intensity magnetic separator, it can be used in paints, plastic, rubber, adhesives and sealants, and agriculture and animal feed industries [17-19].

This mixture can not be used in paper and food industries due to the higher ratio of $\mathrm{Sio}_{2}$ than the required. It can not be also used in ceramic industry due to the higher ratio of $\mathrm{Sio}_{2}$ and $\mathrm{Fe}_{2} \mathrm{O}_{3}$ and the lower ratios of $\mathrm{Cao}$ and $\mathrm{CaCO}_{3}$ than the required ratios.

\subsubsection{Grinding of the Crushed Samples in the Pebble Mill}

A representative sample of $(-1+0) \mathrm{mm}$ size that produced from hammer mill was fed to the pebble mill with different sizes fillent as a grinding media.

The operating parameters were kept constant at a mill speed of $60 \mathrm{rpm}, 20$ minutes grinding time and the ratio of the fillent weight to the ore weight was $2: 1$.
A sample of the product was screened on a $800,630,500$, $315,200,160$ and $63 \mu \mathrm{m}$ screen nest. The results of screening are illustrated in Table 11 and Figure 9.

Table 11. Cum.wt.\% retained and passed for pebble milled ground product.

\begin{tabular}{lllll}
\hline Size fraction, $\boldsymbol{\mu m}$ & wt., gm & wt., $\%$ & c.w.r.\% & c.w.p.\% \\
\hline$(-1000+800)$ & 7 & 2.86 & 2.86 & 100.00 \\
$(-800+630)$ & 26 & 10.63 & 13.49 & 97.14 \\
$(-630+500)$ & 18 & 7.36 & 20.85 & 86.51 \\
$(-500+315)$ & 35.5 & 14.51 & 35.36 & 79.15 \\
$(-315+200)$ & 13 & 5.31 & 40.68 & 64.64 \\
$(-200+160)$ & 20 & 8.18 & 48.86 & 59.32 \\
$(-160+100)$ & 58 & 23.71 & 72.57 & 51.14 \\
$(-100+63)$ & 52.5 & 21.46 & 94.03 & 27.43 \\
$(-63+0)$ & 14.6 & 5.97 & 100.00 & 5.97 \\
$\sum$ & 244.6 & 2.86 & 2.86 & 100.00 \\
\hline
\end{tabular}

c.w.r. $\%=$ cumulative weight retained percent

c.w.p. $\%=$ cumulative weight pass percent

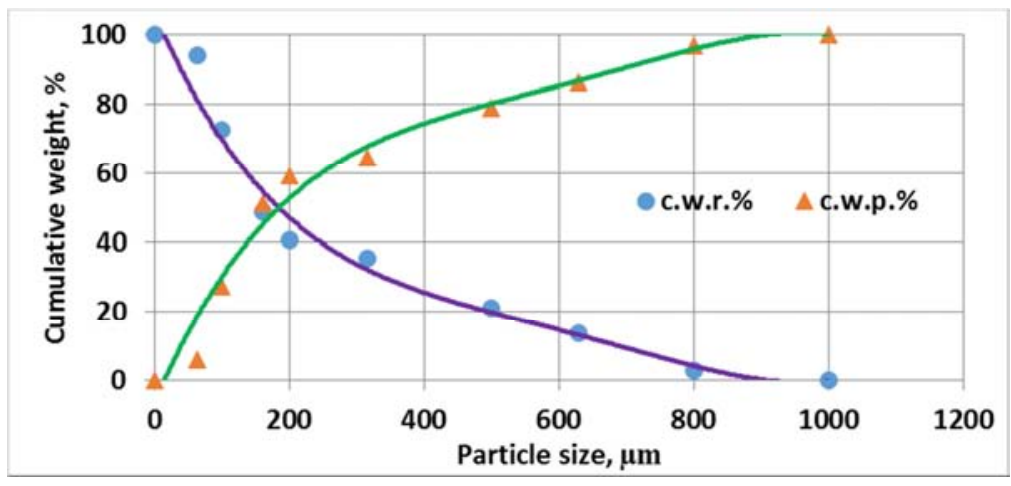

Figure 9. Cum.wt.\% retained and passed for pebble milled ground product.

The size greater than $200 \mu \mathrm{m}$ of the product was ground again in the pebble mill in a closed circuit with a $200 \mu \mathrm{m}$ screen. From the represented results in Figure 9. the grinding efficiency of the pebble mill is calculated to be 1.17 . The pebble milled product of $-200 \mu \mathrm{m}$ size was agitated in cold and hot waters under conditions shown in Table 12.

Table 12. Agitation conditions of -200 $\mu$ m pebble milled product.

\begin{tabular}{lll}
\hline Condition & Cold water & Hot water \\
\hline Weight of the sample before leaching $(\mathrm{gm})$ & 247 & 248 \\
Volume of water, $\left(\mathrm{cm}^{3}\right)$ & 1000 & 1000 \\
Speed of agitation, $(\mathrm{rpm})$ & 1200 & 1200 \\
Time of agitation, $(\mathrm{hr})$ & 2 & 1 \\
\hline
\end{tabular}

The product of agitation was filtered, dried and weighed. It is found that the dried material did not leach either in cold in hot water.

\subsection{Magnetic Separation}

Low intensity wet magnetic separator (Davis magnetic tube) and high intensity magnetic separator (Dry belt boxmag) were applied on the ore.

It was found that the results of low intensity magnetic separation on $-63 \mu \mathrm{m}$ either cold leached or hot leached were unreasonable. A representative sample of magnetic and nonmagnetic products were chemically analyzed using XRF apparatus. Table 13 and Figure 10 clears the results of recovered ratios for the most important elements in the sample.

From the results that tabulated in Tables 13 and 14 and represented in Figures 10 and 11 it is clear that:

The Cao percent is increased from $55.13 \%$ to $55.28 \%$ with a recovery of $51.60 \%$ and weight recovery of $51.46 \%$. At the same time the Cao percent is decreased to $54.97 \%$ with a recovery of $48.4 \%$ in the magnetic product. With respect to $\mathrm{Fe}_{2} \mathrm{O}_{3}$ its ratio is decreased from $0.11 \%$ to $0.05 \%$ with a recovery of $23.77 \%$.

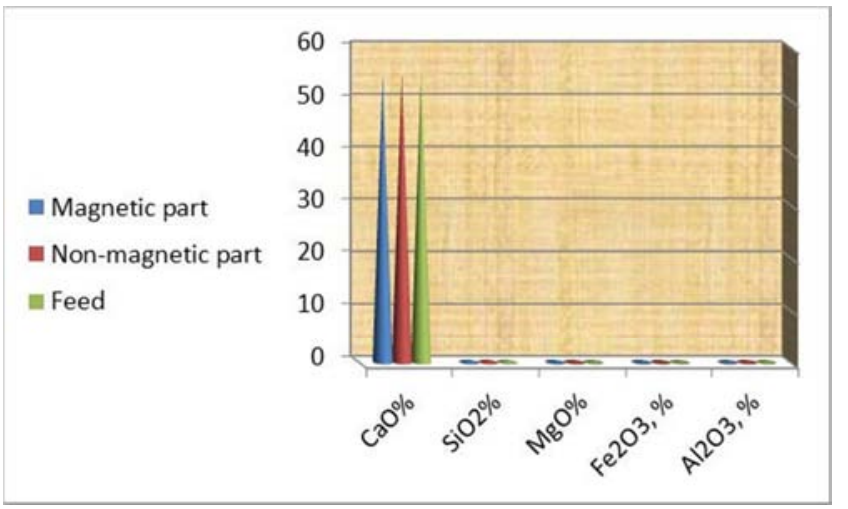

Figure 10. Chemical analysis of the most important elements in the products of dry magnetic separation process using Dry belt Boxmag Rapid Apparatus. 
Table 13. Chemical analysis of the most important elements in the product of dry magnetic separation process using Dry belt Boxmag Rapid Apparatus.

\begin{tabular}{llllllllll}
\hline \multirow{2}{*}{ Sample } & \multirow{2}{*}{ wt., $\%$} & \multicolumn{2}{l}{ Chemical Composition } & & & & & \\
\cline { 3 - 9 } & & $\mathbf{C a O} \%$ & $\mathbf{S i O}_{\mathbf{2}} \mathbf{\%}$ & $\mathbf{M g O} \%$ & $\mathbf{F e}_{2} \mathbf{O}_{\mathbf{3}}, \mathbf{\%}$ & $\mathbf{A l}_{\mathbf{2}} \mathbf{O}_{\mathbf{3}}, \mathbf{\%}$ & $\mathbf{C a C O}_{\mathbf{3}}, \mathbf{\%}$ & Purity degree \\
\hline Magnetic Part & 48.54 & 54.97 & 0.53 & 0.21 & 0.17 & 0.23 & 98.16 & Medium purity \\
Non-magnetic Part & 51.46 & 55.28 & 0.54 & 0.18 & 0.05 & 0.19 & 98.71 & High purity \\
Head sample & 100 & 55.13 & 0.54 & 0.19 & 0.11 & 0.21 & 98.45 & Medium purity \\
\hline
\end{tabular}

In the non-magnetic part. In the same time this ratio increased to $0.17 \%$ with a recovery of $76.23 \%$ in the magnetic part. This means that the Dry Belt Boxmag magnetic separator reduced $\mathrm{Fe}_{2} \mathrm{O}_{3}$ to one quarter of its value

Table 14. Recovery ratios of the most important elements in the product of dry magnetic separation process using Dry Belt Boxmag Rapid Appratus.

\begin{tabular}{|c|c|c|c|c|c|c|}
\hline \multirow{2}{*}{ Sample } & \multirow{2}{*}{ wt., \% } & \multicolumn{5}{|c|}{ Component Recovery } \\
\hline & & $\mathrm{CaO} \%$ & $\mathrm{SiO}_{2} \%$ & MgO\% & $\mathrm{Fe}_{2} \mathrm{O}_{3}, \%$ & $\mathrm{Al}_{2} \mathrm{O}_{3}, \%$ \\
\hline Magnetic Part & 48.54 & 48.40 & 48.07 & 52.39 & 76.23 & 53.31 \\
\hline Non-magnetic Part & 51.46 & 51.60 & 51.93 & 47.61 & 23.77 & 46.69 \\
\hline
\end{tabular}

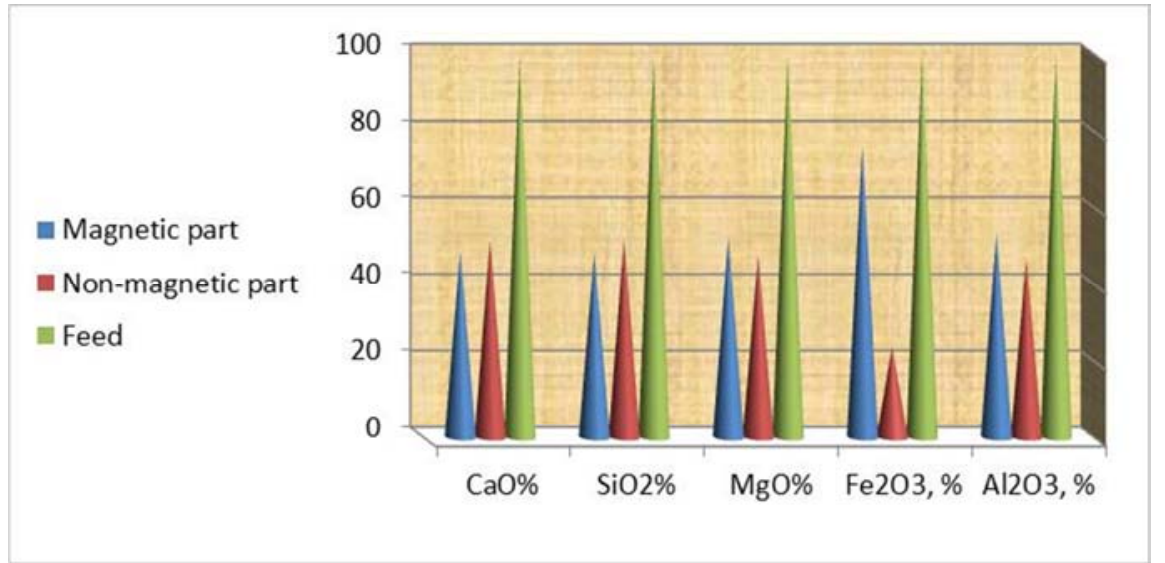

Figure 11. Recovery ratios of the most important elements in the product of dry magnetic separation process using Dry Belt Boxmag Rapid Appratus.

According to the Egyptian general Authority of Mineral Wealth classification the chemical composition of the nonmagnetic product follows the super-high purity $(98.5 \%$ $\mathrm{CaCo}_{3}$ ), but according to the British Geological Surveying classification it follows the high purity category due to the high percent of $\mathrm{Sio}_{2}$. The non-magnetic part of the product can be used in paints, plastic, rubber, adhesives and sealants, and agriculture and animal feed industries [16-19].

This product can not be used in paper and foods due to the high ratio of $\mathrm{Sio}_{2}$. It can not be also used in ceramics industry due to its higher ratios of $\mathrm{Sio}_{2}$ and $\mathrm{Fe}_{2} \mathrm{O}_{3}$ and lower ratios of $\mathrm{Cao}$ and $\mathrm{CaCo}_{3}$ than the required limits.

\subsection{Calcination Process}

Calcination of limestone at $1000^{\circ} \mathrm{C}$ produces a quick lime

$$
\text { Loss due to calcination }=\frac{\text { weight of the sample before calcination-weight after calcination }}{\text { weight of the sample before calcination }} \times 100
$$

Results of $(-500+0) \mu \mathrm{m}$ size calcination are shown in Table 15 and Figure 12.

Table 15. Effect of the temperature on the calcination of $(-500+0) \mu m$ size

\begin{tabular}{llll}
\hline Temp., ${ }^{\circ} \mathbf{C}$ & Weight of sample before calcinations & Weight of sample after calcinations & \% Loss in weight \\
\hline 900 & 100.5021 & 58.6847 & 41.61 \\
1000 & 103.2108 & 58.6226 & 43.20 \\
1050 & 112.9843 & 64.0347 & 43.32 \\
\hline
\end{tabular}

that can be used in many industries such as iron and steel, paper, sugar production, preparation of some dyes, as an acidic modifier for soil acidity and as assistant for fertilizer analysis in the soil (5). It is also used to inhance the analysis of the anthrax dead animals, as a constructional material, glass making, furnaces lining industry and as a modifier for soil alkilily [12].

\subsubsection{Calcinations of -500 $\mu \mathrm{m}$ Size}

Samples of $-500 \mu \mathrm{m}$ size taken from the pebble mill product were calcined for three hours at different temperatures $\left(900,1000\right.$ and $\left.1050^{\circ} \mathrm{C}\right)$. The loss due to calcination was calculated as: in the magnetic product. Pertaing to the other elements, it was no change in the recovery ratios of $\mathrm{Sio}_{2}, \mathrm{Al}_{2} \mathrm{O}_{3}$, and $\mathrm{Mgo}$ either in the magnetic or non-magnetic products. 
The results of Table 15 and Figure 12 show that the loss in weight due to calcination process increased from $41.61 \%$ to $43.20 \%$ as the temperature increased from 900 to $1000^{\circ} \mathrm{c}$. Increasing the temperature to $1050^{\circ} \mathrm{C}$ led to a tough increase in the loss weight. This means that the optimum temperature of calcination is $1000^{\circ} \mathrm{C}$.

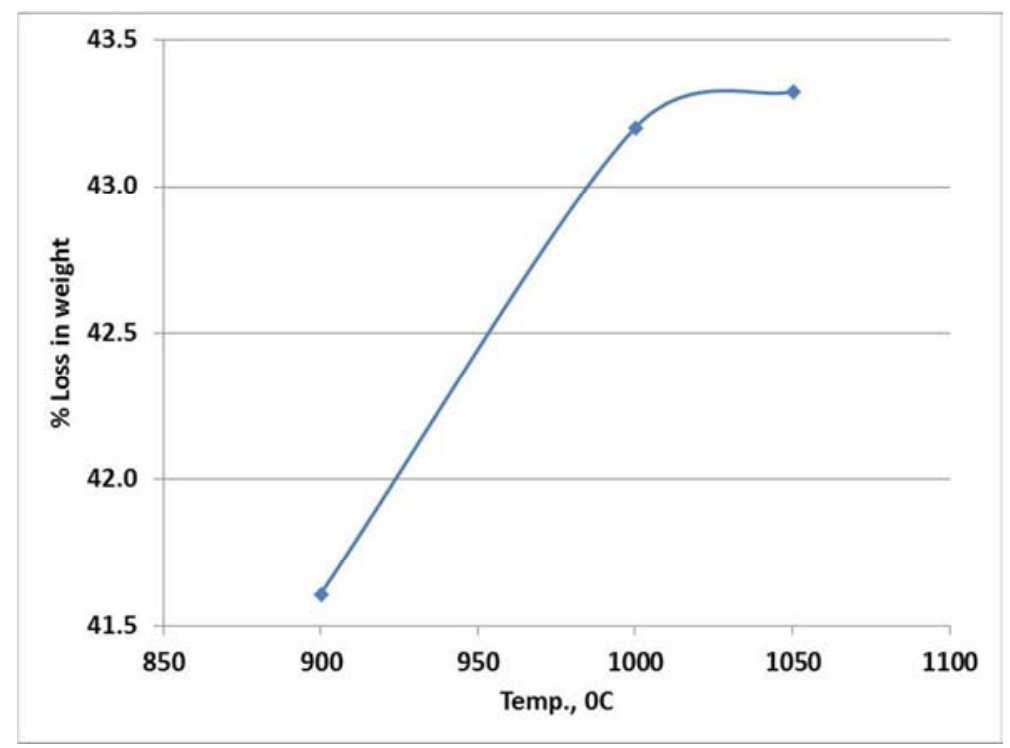

Figure 12. Effect of the temperature on the calcination of $(-500+0) \mu m$ size.

Representative calcined samples at the different studied temperatures were chemically analyzed using XRF and shown in Table 16 and Figure 13.

Table 16. XRF chemical composition for the most important elements for (-500+0) $\mu m$ calcined product at different temperatures.

\begin{tabular}{|c|c|c|c|c|c|c|}
\hline \multirow{2}{*}{ Temp., ${ }^{\circ} \mathrm{C}$} & \multirow{2}{*}{ \% Loss in weight } & \multicolumn{5}{|c|}{ Chemical Composition } \\
\hline & & $\mathrm{CaO} \%$ & $\mathrm{SiO}_{2} \%$ & MgO $\%$ & $\mathrm{Fe}_{2} \mathrm{O}_{3}, \%$ & $\mathrm{Al}_{2} \mathrm{O}_{3}, \%$ \\
\hline 900 & 41.61 & 82.79 & 0.85 & 0.27 & 0.22 & 0.30 \\
\hline 1000 & 43.20 & 89.44 & 0.94 & 0.29 & 0.24 & 0.33 \\
\hline 1050 & 43.32 & 89.82 & 0.94 & 0.28 & 0.25 & 0.34 \\
\hline
\end{tabular}

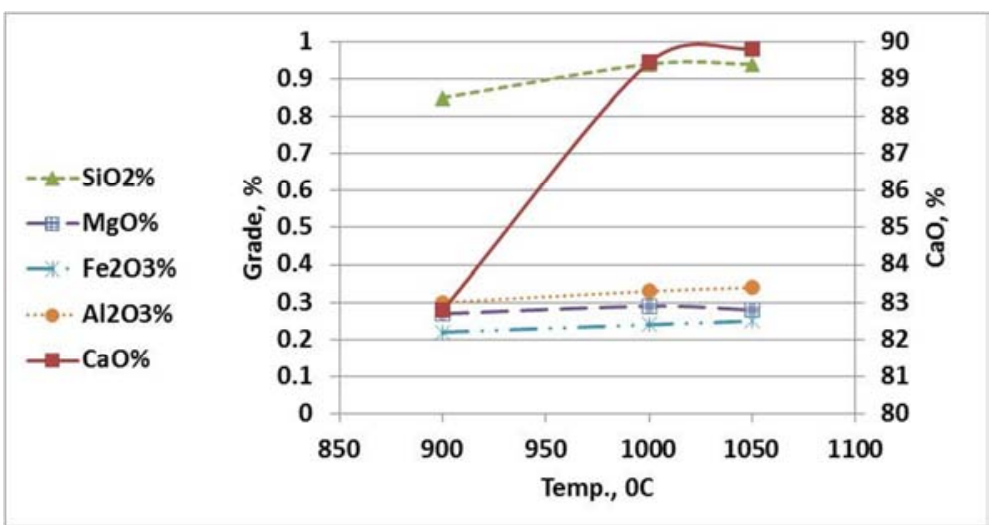

Figure 13. Chemical analysis of the most important elements using XRF for $(-500+0) \mu m$ calcined product.

Results of Table 16 represent the chemical composition for the most important elements for the calcined product. These results are represented in Figure 13. From this Figure it is clear that the $\mathrm{Cao} \%$ increased from $82.79 \%$ to $89.44 \%$ by increasing the temperature from 900 to $1000^{\circ} \mathrm{C}$. Increasing the temperature to $1100^{\circ} \mathrm{C}$ increased the $\mathrm{Cao} \%$ slightly. Consequently, $900^{\circ} \mathrm{C}$ can be considered as the optimum calcination temperature for $(-500+0) \mu \mathrm{m}$.

Table 17 clears the component recovery of the most important constituents for $(-500+0) \mu \mathrm{m}$ calcined product at the different studied degrees of temperature. From the results of Table 17 and Figure 14 it is clear that the recovery of Cao, $\mathrm{Al}_{2} \mathrm{O}_{3}, \mathrm{Fe}_{2} \mathrm{O}_{3}$ in the calcined sample increased with increasing the temperature up to the optimum temperature $\left(1000^{\circ} \mathrm{C}\right)$. the recovered ratios of $\mathrm{Mgo}$ and $\mathrm{Sio}_{2}$ increased to a certain limit (up to $1000^{\circ} \mathrm{C}$ ) then decreased, These results clear also that calcination process of $(-500+0) \mu \mathrm{m}$ size did not get red of enough amounts of harmful elements. Most of the lime in the specimen is recovered at $1000^{\circ} \mathrm{C}$ with a recovery ratio $89.44 \%$ and a weight recovery of $56.80 \%$. 
Table 17. Component recovery for the most important elements in the calcined product of $(-500+0) \mu \mathrm{m}$.

\begin{tabular}{|c|c|c|c|c|c|c|}
\hline \multirow{2}{*}{ Temp., ${ }^{\circ} \mathrm{C}$} & \multirow{2}{*}{$\%$ Loss in weight } & \multicolumn{5}{|c|}{ Component recovery } \\
\hline & & $\mathrm{CaO} \%$ & $\mathrm{SiO}_{2} \%$ & MgO\% & $\mathrm{Fe}_{2} \mathrm{O}_{3}, \%$ & $\mathrm{Al}_{2} \mathrm{O}_{3}, \%$ \\
\hline 900 & 41.61 & 87.69 & 85.57 & 82.98 & 91.76 & 83.41 \\
\hline 1000 & 43.20 & 92.15 & 92.06 & 86.69 & 97.37 & 89.26 \\
\hline 1050 & 43.32 & 92.35 & 91.86 & 83.53 & 99.19 & 91.77 \\
\hline
\end{tabular}

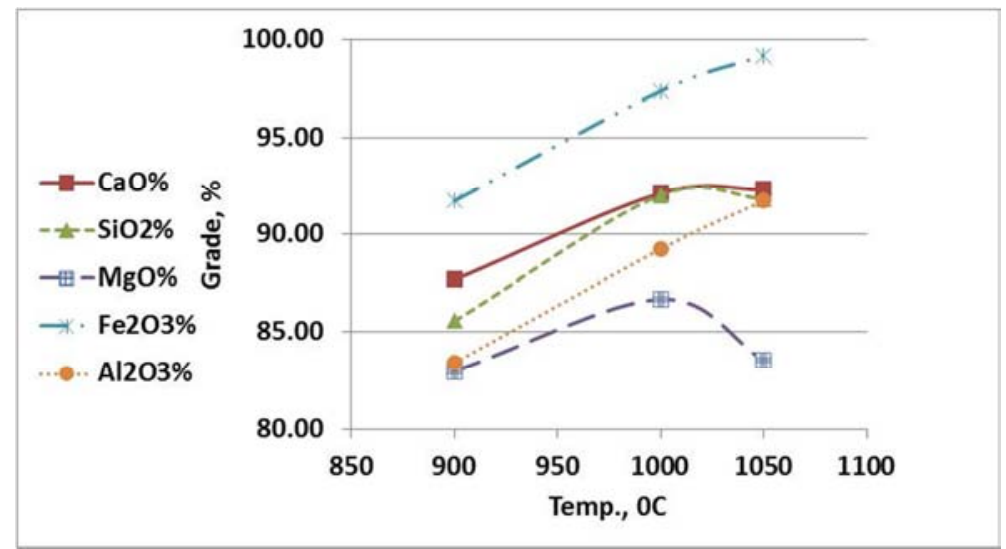

Figure 14. Recovery ratios of the most important elements for $(-500+0) \mu m$ calcined product.

\subsubsection{Calcinations of $(-200+0) \mu m$ Size}

Final results of $(-200+0) \mu \mathrm{m}$ calcination process are shown in Table 18 and Figure 15. From these results it is clear that the loss in weight due to calcination increased from $11 \%$ to
$41.19 \%$ with increasing the calcination temperature from $800^{\circ}$ to $900^{\circ} \mathrm{C}$. The results show also that the optimum calcination temperature is $1000^{\circ} \mathrm{C}$.

Table 18. Effect of the temperature on the calcination of $(-200+0) \mu m$ size.

\begin{tabular}{lllllll}
\hline \multirow{2}{*}{ Temp., ${ }^{\circ} \mathbf{C}$} & \multicolumn{2}{l}{ Weight of sample before calcinations } & \multicolumn{3}{l}{ Weight of sample after calcinations } \\
\cline { 2 - 6 } & Sample A & Sample B & Mean & Sample A & Sample B & Mean \\
\hline 800 & 79.54 & 80.88 & 80.21 & 70.86 & 71.91 & 71.38 \\
900 & 85.04 & 84.56 & 84.80 & 50.62 & 49.13 & 49.88 \\
1000 & 78.29 & 88.42 & 83.36 & 44.72 & 50.33 & 47.53 \\
\hline
\end{tabular}

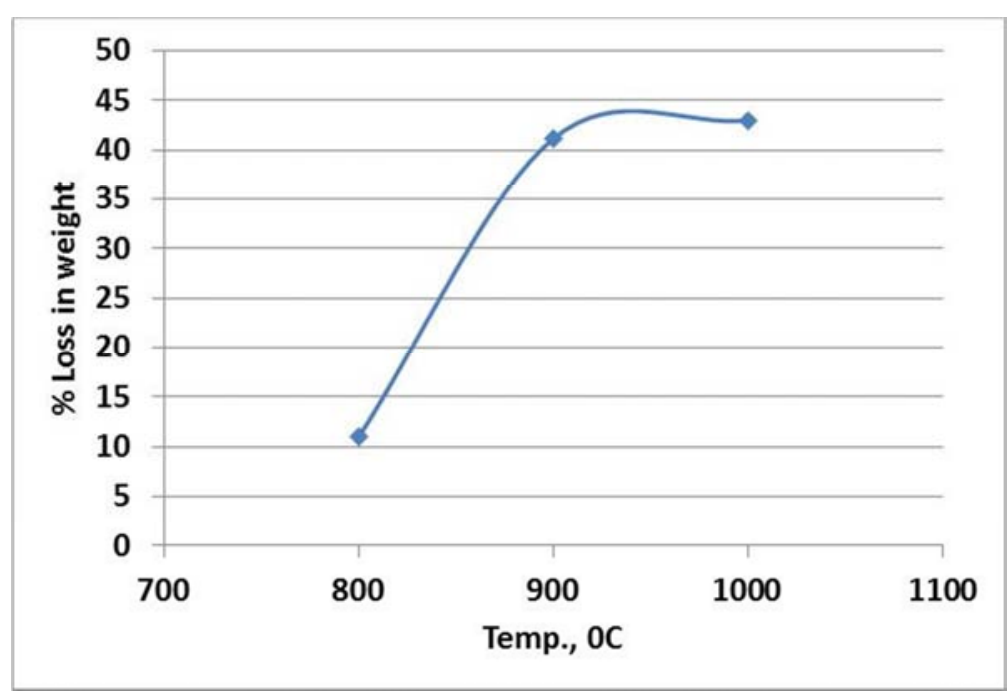

Figure 15. Effect of the temperature on the calcination of $(-200+0) \mu m$ size.

The representative samples of the products calcined at $800^{\circ}$, $900^{\circ}$, and $1000^{\circ} \mathrm{C}$ for three hours were chemically analyzed using XRF. These results are shown in Table 19 and Figure 16. From these results it is clear that the percentage of Cao increased from $60.75 \%$ to $79.69 \%$ with increasing the temperature from $900^{\circ} \mathrm{C}$ to $1000^{\circ} \mathrm{C}$. Increasing the temperature to $1000^{\circ} \mathrm{C}$ increased the $\mathrm{Cao} \%$ to $85.32 \%$. Consequently, $1000^{\circ} \mathrm{C}$ can be considered as the optimum one. 
Table 19. Chemical composition for the most important elements for $(-200+0)$ um calcined product at different temperatures.

\begin{tabular}{|c|c|c|c|c|c|c|}
\hline \multirow{2}{*}{ Temp., ${ }^{\circ} \mathrm{C}$} & \multirow{2}{*}{ \% Loss in weight } & \multicolumn{5}{|c|}{ Chemical Composition } \\
\hline & & $\mathrm{CaO} \%$ & $\mathrm{SiO}_{2} \%$ & MgO\% & $\mathrm{Fe}_{2} \mathrm{O}_{3}, \%$ & $\mathbf{A l}_{2} \mathbf{O}_{3}, \%$ \\
\hline 800 & 11.00 & 60.75 & 0.57 & 0.20 & 0.14 & 0.20 \\
\hline 900 & 41.19 & 79.69 & 0.66 & 0.27 & perat 0.23 & 0.23 \\
\hline 1000 & 42.99 & 85.32 & 0.71 & 0.25 & 0.20 & 0.25 \\
\hline
\end{tabular}

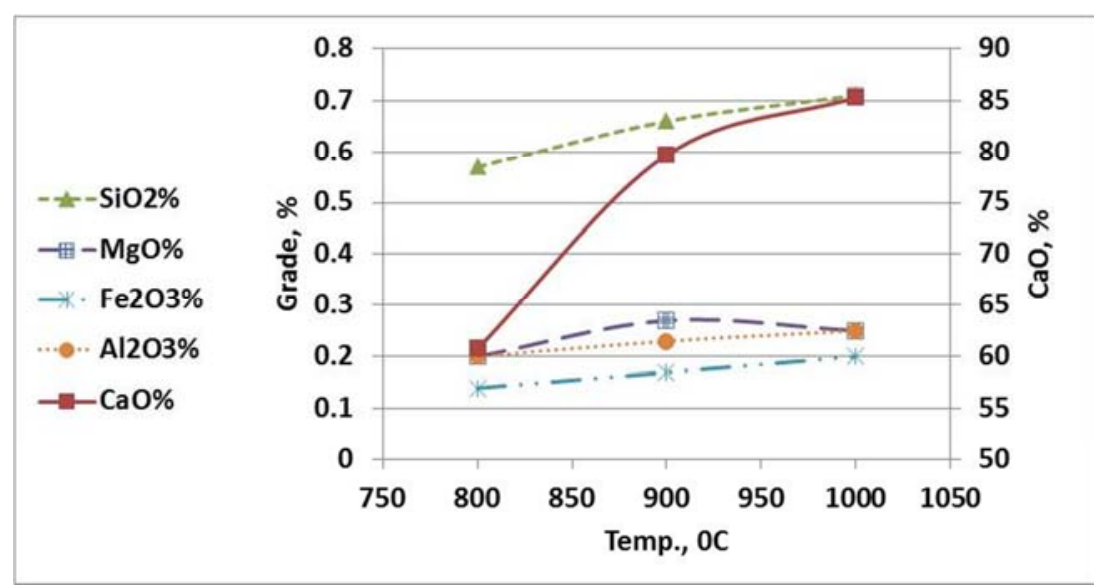

Figure 16. Chemical analysis for the most important elements for (-200+0) $\mu m$ calcined product.

From the results of Table 20 which represented in Figure 17 it is clear that the component recovery of $\mathrm{Cao}, \mathrm{Al}_{2} \mathrm{O}_{3}$ and $\mathrm{Fe}_{2} \mathrm{O}_{3}$ in the calcined sample decreased with increasing the temperature up to $900^{\circ}$ (the optimum temperature) then increased. The component recovery of Mgo decreased absdutly with increasing the temperature. These results show also that the calcinations process at $1000^{\circ} \mathrm{C}$ dismissed about one third of the harmful elements $\left(\mathrm{Al}_{2} \mathrm{O}_{3}\right.$ and $\left.\mathrm{Sio}_{2}\right)$ and a quarter of $\mathrm{Mgo}$ and fifth of $\mathrm{Fe}_{2} \mathrm{O}_{3}$ from the calcined ore of size $(-200+0) \mu \mathrm{m}$. Most of the lime in the calcined specimen $(88.23 \%)$ is recovered at a temperature of $900^{\circ} \mathrm{C}$.

Table 20. Component recovery for the most important elements in the calcined limestone of size (-200+0) $\mu m$ at different temperatures.

\begin{tabular}{lllllll}
\hline \multirow{2}{*}{ Temp. ${ }^{\circ} \mathbf{C}$} & \multirow{2}{*}{$\%$ Loss in weight } & \multicolumn{2}{l}{ Component recovery } & & \\
\cline { 2 - 6 } & & $\mathbf{C a O} \%$ & $\mathbf{S i O}_{\mathbf{2}} \%$ & $\mathbf{M g O} \%$ & $\mathbf{F e}_{\mathbf{2}} \mathbf{O}_{\mathbf{3}}, \mathbf{\%}$ \\
\hline 800 & 11.00 & 98.07 & 87.47 & 93.68 & 89.00 \\
900 & 41.19 & 85.01 & 66.92 & 83.57 & 71.41 \\
1000 & 42.99 & 88.23 & 69.79 & 75.01 & 64.41 & 81.44 \\
\hline
\end{tabular}

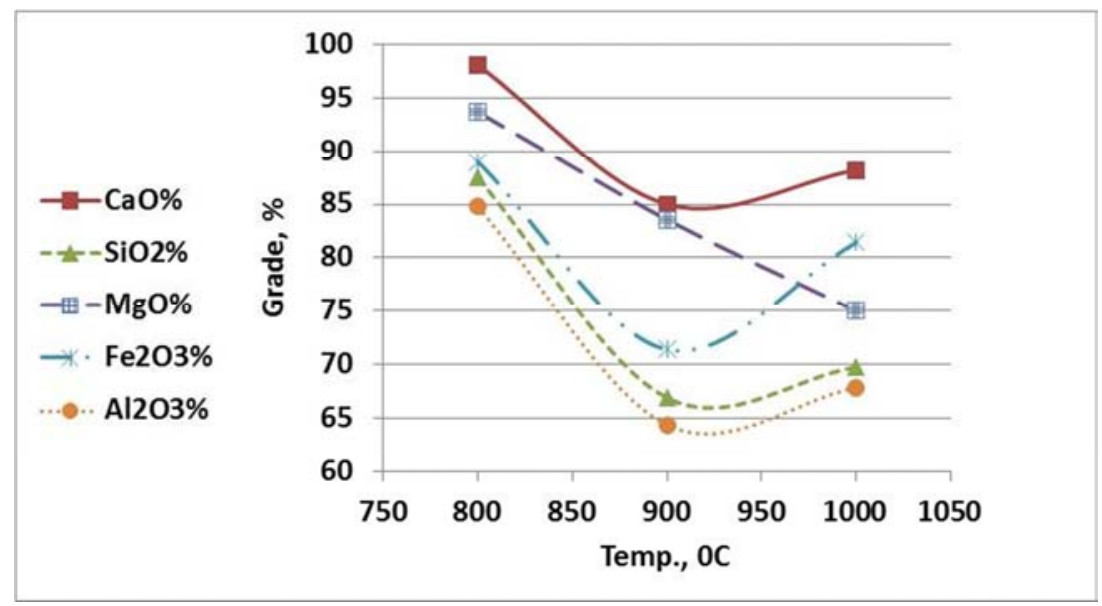

Figure 17. Recovery ratios of the most important elements for $(-200+0) \mu m$ calcined product at different temperatures.

\section{Conclusion}

From the obtained results and their discussions, the following conclusions can be drawn:

1. The limestone deposits located in Beni-Khaled, El-
Minya Governorate can be considered as a potential high-grade calcium carbonate.

2. Results of crushing the limestone ore cleared that, adding $(-6+4) \mathrm{cm}$ and $(-4+2) \mathrm{cm}$ sizes which represent $38.07 \%$ of the head sample produces a proper mixture 
for different industrial uses such as paints, paper, plastic, rubber, adhesive and sealants, agriculture and animal feed. This product can not be used in food and ceramics industries.

3 . The high quality sizes $(-1+0.5) \mathrm{mm}$ and ($0.2+0.063) \mathrm{mm}$ ground ore which represent $52.03 \%$ of the head sample can be added to produce a mixture proper for different industries such as paints, plastic, rubber, adhesive and sealants and animal feed. This mixture can not be used for paper, food and ceramics industries.

4. Low intensity magnetic separation process is not able to purify the ore from its iron traces.

5. Dry Belt Boxmag Rapid separator succeeded to purify the ore from its iron traces. A non-magnetic product liable for some important industries such as paints, rubber, adhesive and sealants, agriculture and animal feed was produced. This product does not agree with the requirements of paper, food and ceramics industry,

6. Calcination of the ore produced a lime proper for many modern industries such as iron making, paper, sugar, tanning and treatment of sewage sludge and tailings of industrial operations. It can be also used in the preparation of some types of dyes and bleaching, as a modifier for soil acidly, and as accelerator for analyzing the animals buried cadaver that died by anthrax.

7. Uses of limestone ore should be oriented to the beneficial industries instead of using it as a building material (brick).

\section{Acknowledgements}

The present research work was supported by the Egyptian Academy of Science and Technology with Assiut University, Faculty of Engineering to establish Centre of Evaluation and Upgrading Ores in South Valley (grant \# 37). The authors would like to thank Eng. Nourhan Ashraf, Assistant lecturer at Mining \& Metallurgical Engineering Dept. Technicians in mineral processing labs are also appreciated.

\section{References}

[1] The guide (Investment) map for limestone ore in Egypt. Egyptian General Authority of Mineral Wealth, Academy of Scientific Research and Technology.

[2] D. S. Rao, T. V., Vijayakumar, S., Prabhakar, and Bhaskar Raju, "Geochemical assessment of siliceous limestone sample for cement making", Chin. J. Geochem. 30, pp 033-039.

[3] High purity limestone quest industrial minerals, Dec. 2011.pp 48-52.
[4] A. M. Ali Mahrous and Hyung-Sik yang, "A study of some Egyptian carbonate rocks for the building construction industry", Int. J. Mining Science and Technol., 24, 2014, 467470.

[5] Syed Mohamad. A., El Sageer, H. and y. Hussein Mamdouh, "Evaluation of the engineering properties of some Egyptian limestone as controlling factors for highways construction and cement industry", The $3^{\text {rd }}$ Int. Conf. for Building and construction Cairo, 1996, pp. 323-332.

[6] M. Mahrous, M. Mostafa Tantawi and H. El-Sagger, "Evaluation of the engineering properties of some Egyptian limestones as construction materials for highway pavements", Constr Build Mater., 24(2010), pp. 2598-2603.

[7] Informations collected from the data sheets available on line for 198 calcium carbonate products.

[8] Gaber, M. A. Wahab, "Characterization of El-Minia limestone for manufacturing paper filler", Egyptian Journal of Petroleum.

[9] Characterization of Calcium Carbonate rocks, East El-Minya deposits for possibility uses as industrial raw materials.

[10] Scientific Opinion on re-evaluation of calcium carbonate as a food additive, EFSA Panel on food additives an Nutrient Sources added to food (ANS, EFSA) Journal, 9, 7, 2011, 2318.

[11] E. A. H. El-Rahiem, M. A. Arafa and M. M. Farhat, "Flotation of fine particles of groan calcium carbonate as added value of filler in some industries", Mineral Processing and Extractive Metallurgy (Trans. Inst. Min. Metall., c), vol. 115 No. 3,(2006) pp. 161-164.

[12] Chatterjee, k. k.,"Uses of industrial minerals, rock and fresh water", Nova Science publishers, Inc1, New York, pp. 167174, (2009).

[13] British Geological Survey, Industrial Minerals, High purity limestone, (2011).

[14] Mukerjee, S., "Industrial Mineralogy:Mineral Processing, Beneficiations and other related mineral usage", Applied Mineralogy:Applications in industry.

[15] Bilqees, R., Tahirkheli, T., Pirzada, N., and Abbas, S. M., "Industrial applications of Abbottabad limestone, Utilizing its chemical and Engineering properties", Journal of Himalayan Earth Science, Vol. 45, No. 1, pp. 91-96, (2012).

[16] "Indian Minerals yearbook", Government of India, Ministry of Mines, India Bureau of Mines, 52, p. 34, (2013).

[17] www.longcliffe, High purity limestone products.

[18] El-kadi, T. M., "Industrial minerals and rocks", El-malek Abdel-Aziz University, Kingdom of Saudi Arabya.

[19] Report for limestone deposits for cement manufacture by National Council of Cement Building Materials, New Delhi, May 2001. 